\title{
Evaluation of the ERA5 reanalysis as a potential reference dataset for hydrological modelling over North America
}

\author{
Mostafa Tarek, François P. Brissette, and Richard Arsenault \\ École de technologie supérieure, 1100 Notre-Dame West, Montréal, Québec, H3C 1K3, Canada \\ Correspondence: Mostafa Tarek (mostafa-tarek-gamaleldin.ibrahim.1@ens.etsmtl.ca)
}

Received: 19 June 2019 - Discussion started: 10 July 2019

Accepted: 10 April 2020 - Published: 14 May 2020

\begin{abstract}
The European Centre for Medium-Range Weather Forecasts (ECMWF) recently released its most advanced reanalysis product, the ERA5 dataset. It was designed and generated with methods giving it multiple advantages over the previous release, the ERA-Interim reanalysis product. Notably, it has a finer spatial resolution, is archived at the hourly time step, uses a more advanced assimilation system and includes more sources of data. This paper aims to evaluate the ERA5 reanalysis as a potential reference dataset for hydrological modelling by considering the ERA5 precipitation and temperatures as proxies for observations in the hydrological modelling process, using two lumped hydrological models over 3138 North American catchments. This study shows that ERA5-based hydrological modelling performance is equivalent to using observations over most of North America, with the exception of the eastern half of the US, where observations lead to consistently better performance. ERA5 temperature and precipitation biases are consistently reduced compared to ERA-Interim and systematically more accurate for hydrological modelling. Differences between ERA5, ERA-Interim and observation datasets are mostly linked to precipitation, as temperature only marginally influences the hydrological simulation outcomes.
\end{abstract}

\section{Introduction}

Hydrological science knowledge has long been anchored in the need for observations (Wood, 1998). Observations and measurements of all components of the hydrological cycle have been used to gain a better understanding of the physics and thermodynamics of water and energy exchange between the land and the atmosphere (e.g. Luo et al., 2018; McCabe et al., 2017; Siegert et al., 2016; Zhang et al., 2016; Stearns and Wendler, 1988). In particular, measurement of precipitation and temperature at the earth's surface has been a critical part of the development of various models describing the vertical and horizontal movements of water. Hydrological models, for example, are routinely used to transform liquid and solid precipitation into streamflows, using other variables such as temperature, wind speed and relative humidity to increase their predictive skill (Singh and Woolhiser, 2002). Throughout the last several decades, such data have essentially been provided by surface weather stations (Citterio et al., 2015). However, and despite the utmost importance of observed data for hydrological sciences, a net decline in the number of stations in the historical climatology network of monthly temperature datasets has been observed since the beginning of the 21st century (Menne et al., 2018; Lins, 2008). Perhaps more importantly, data from the NASA-GISS surface temperature analysis show a particularly large decrease in the number of stations with a long record, a decline starting in 1980. Stations with long records are critical for monitoring trends in hydroclimatic variables (Whitfield et al., 2012; Burn et al., 2012). In addition, the GISS data document a slow but consistent decrease in the percent of hemispheric area located within $1200 \mathrm{~km}$ of a reporting station since the middle of the 20th century (GISS, 2019).

On the upside, other sources of data have steadily appeared to compensate for this worrisome diminishing trend in surface weather stations (e.g. Beck et al., 2017a, b, 2019b; Sun et al., 2018; Lespinas, 2015). Interpolated gridded datasets of precipitation and temperature are now common. They allow some information from regions with good network coverage to be extended, to some extent, towards areas with less information. Interpolated datasets, however, do not create new in- 
formation, no matter how complex and how much additional information is used in the interpolation schemes (Essou et al., 2016a; Newman et al., 2015). Remotely sensed datasets have long carried the hope of bringing relevant hydrometeorological information over large swaths of land, up to the global scale, and over regions with absent or low-density observational networks (Lettenmaier et al., 2015). There are now several global or near-global precipitation datasets derived from various satellites, with spatial resolutions varying between 0.125 and $1^{\circ}$ (Sun et al., 2018). Ground-radar-based products are also becoming more common and are available at an even higher resolution (Beck et al., 2019a). All remotely sensed precipitation datasets do however only provide indirect measurements of the target variable. They typically provide biased estimates, and ground stations are often needed to correct the remotely sensed estimates (Fortin et al., 2015).

Atmospheric reanalysis is another product that has generated interest increasingly in the recent decade. Reanalyses combine a wide array of measured and remotely sensed information within a dynamical-physical coupled numerical model. They use the analysis part of a weather forecasting model, in which data assimilation forces the model toward the closest possible current state of the atmosphere. A reanalysis is a retrospective analysis of past historical data making use of the ever-increasing computational resources and more recent versions of numerical models and assimilation schemes. Reanalyses have the advantage of generating a large number of variables not only at the land surface, but also at various vertical atmospheric levels. Data assimilated in a reanalysis consist mostly of atmospheric and ocean data and do not typically rely on surface data, such as measured by weather stations. Reanalysis outputs are therefore not directly dependent on the density of surface observational networks and have the potential to provide surface variables in areas with little to no surface coverage. Several modelling centres now provide reanalyses with varying spatial and temporal scales (Lindsay et al., 2014; Chaudhuri et al., 2013). Reanalyses and observations share similarities and differ in other aspects (Parker, 2016). Reanalyses have increasingly been used in various environmental and hydrological applications (e.g. Chen et al., 2018; Ruffault et al., 2017; Emerton et al., 2017; Di Giuseppe et al., 2016). They are commonly used in regional climate modelling, weather forecasting and, more recently, as substitutes for surface precipitation and temperature in various hydrological modelling studies (Chen et al., 2018; Essou et al., 2016b, 2017; Beck et al., 2017a). They have been shown to provide good proxies to observations and even to be superior to interpolated (from surface stations) datasets in regions with sparse network surface coverage (Essou et al., 2017). Precipitation and temperature outputs from reanalyses have, however, been shown to be inferior to observations in regions with good weather station spatial coverage (Essou et al., 2017). The relatively coarse spatial resolution of reanalyses is thought to be partly responsible for this. Amongst all available reanalyses, many stud- ies have shown ERA-Interim (European Centre for MediumRange Weather Forecasts (ECMWF) interim reanalysis) to be the best or amongst the best performing reanalysis products (e.g. Sun et al., 2018; Beck et al., 2017a; Essou et al., 2017, 2016b), arguably the result of its sophisticated assimilation scheme, and despite a spatial resolution inferior to that of most other modern reanalyses. In March 2019, ECMWF released the fifth generation of its reanalysis (ERA5) over the 1979-2018 period (Hersbach and Dee, 2016). ERA5 incorporates several improvements over ERA-I (see Sect. 3 of this paper).

Of particular interest to the hydrological community are the largely improved spatial $(30 \mathrm{~km})$ and temporal $(1 \mathrm{~h})$ resolutions. The spatial resolution is now similar to or better than that of most observational networks in the world, with the exception of some parts of Europe and the United States. The hourly temporal resolution matches that of the best observational networks. In the United States and Canada, for example, there are currently no readily available observationderived precipitation and temperature datasets at the subdaily timescale, and sub-daily records are not consistently available for weather stations. In particular, the hourly temporal resolution, if proven accurate, could open the door to many applications, and notably for modelling small watersheds for which a daily resolution is not adequate. Such watersheds are expected to be especially impacted by projected increases in extreme convective events resulting from a warmer troposphere in a changing climate. Some early results from ERA5 have shown that it outperforms other reanalysis sets and its predecessor ERA-I (Albergel et al., 2018; Olausen, 2018; Urraca et al., 2018).

\section{Study objectives}

This work aims at providing a first evaluation of the ERA5 reanalysis over the 1979-2018 period with an emphasis on hydrological modelling at the daily scale. Even though the hourly temporal scale brings many potential applications for hydrological studies, a first step in the evaluation of ERA5 precipitation and temperature datasets is performed at the daily scale. The daily scale allows for a comparison against other North American datasets available at the same temporal resolution, as well as against results from previous studies. In addition, validation at the hourly scale over North America presents additional difficulties, as discussed above, due to the absence of US or Canadian datasets at this resolution and to the absence of recorded hourly precipitation for many weather stations. In Canada, for example, fewer than $15 \%$ of weather stations have archived hourly variables, and hourly precipitation records contain particularly large ratios of missing data, thus complicating the validation at the regional scale. Consequently, the objectives of this study are to 


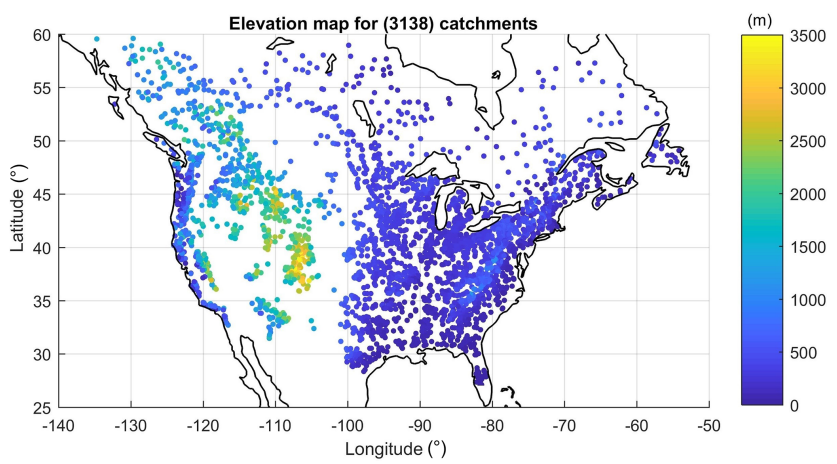

Figure 1. Watershed locations and their mean elevations over Canada and the United States (each dot represents the watershed centroid).

1. provide a first assessment of the potential of ERA5 to provide an accurate representation of precipitation and temperature fields at the daily temporal scale;

2. evaluate the hydrological modelling potential of ERA5 precipitation and temperature datasets over a large set of hydrologically heterogeneous watersheds using two lumped hydrological models; and,

3. based on the above results, document any spatial variability in dataset performance and quantify improvements compared to ERA-I.

\section{Methods and data}

\subsection{Data and study area}

The goal of this study is to evaluate the ERA5 reanalysis product as a substitute for observed data and to compare its properties to those of the older ERA-Interim reanalysis for hydrological modelling uses. Therefore, the ERA5, ERA-Interim and observed (weather station) meteorological datasets were used and basin-averaged over 3138 catchments over Canada and the United States, whose locations and average elevations are shown in Fig. 1. It can be seen that there is a good coverage of the entire domain, although some sparsely populated areas in northern Canada and in the United States Midwest have a lower density of hydrometric gauges.

The hydrological models used in this study required minimum and maximum daily temperature as well as daily precipitation amounts. ERA-Interim and the observed datasets were already on a daily time step; however, ERA5 is an hourly product and, as such, it was necessary to derive daily values from the hourly data by summing precipitations and taking the maximum and minimum $1 \mathrm{~h}$ temperatures of the day.

\subsubsection{ERA-Interim}

ERA-Interim (ERA-I) is a global atmospheric reanalysis which was released by the ECMWF in 2006 (Dee et al., 2011) in replacement of ERA40. ERA-I introduced an advanced four-dimensional variational (4D-var) analysis assimilation scheme with a $12 \mathrm{~h}$ time step. It computes 60 vertical levels from the surface up to $0.1 \mathrm{hPa}$. Its horizontal resolution is approximately $80 \mathrm{~km}$. Precipitation and temperature are available at a $12 \mathrm{~h}$ time step and were aggregated to the daily scale in this work. The production of ERA-I will cease in August 2019, thus providing temporal coverage from 1 January 1999 until August 2019.

\subsubsection{ERA5}

ERA5 is the fifth generation reanalysis from ECMWF. It provides several improvements compared to ERA-I, as detailed by Hersbach and Dee (2016). The analysis is produced at a 1-hourly time step using a significantly more advanced 4Dvar assimilation scheme. Its horizontal resolution is approximately $30 \mathrm{~km}$ and it computes atmospheric variables at 139 pressure levels. Data for the 1979-2018 period were released in March 2019. The 1950-1978 period is expected to be released in the summer of 2019. This paper only looks at 19792018 because outputs of reanalysis prior to 1979 have been put into question due to the more limited availability of data to be assimilated, and notably from earth-observing satellites (e.g. Bengtsson et al., 2004). While ERA5 may solve some of these problems, it is believed that a careful evaluation of inhomogeneity in ERA5 time series would be needed before using pre-1979 data. ERA5 precipitation and temperature were downloaded and aggregated to the daily time step for this work.

\subsubsection{Observed weather data}

The observed weather data come from multiple sources due to the transboundary component in this study. Climate data for catchments in Canada were taken from the CANOPEX database (Arsenault et al., 2016), which includes weather stations from Environment Canada that were post-processed and basin-averaged using Thiessen Polygon weighting. The data cover the period 1950-2010. Any missing values were replaced by the NRCan interpolated climate data product (Hutchinson et al., 2009).

For the United States, historical weather data were taken from the Santa Clara gridded data product (Maurer et al., 2002), as it was shown to be as good as observations for hydrological modelling in a previous study (Essou et al., 2016b) and covers a long time period (1949-2010). The data are interpolated along a regular $0.125^{\circ} \times 0.125^{\circ}$ grid and are then averaged at the catchment scale. 


\subsubsection{Observed streamflow data}

Streamflow records from the United States Geological Survey (USGS) and Environment Canada were used to calibrate the hydrological models at each of the 3138 catchments and evaluate the hydrological modelling performance. The availability of streamflow data was the limiting factor for the simulation length of many catchments, as it varied from 20 years (minimum amount used in these databases) to over 60 years of streamflow records. Missing data were left as they were and were simply not included in the computation of the evaluation metrics.

\subsection{Hydrological models}

In the course of this study, two lumped hydrological models were implemented and calibrated over each of the available catchments because the large-scale aspect of this study precluded the widespread implementation of distributed models. Although ERA5's spatial resolution is more refined than ERA-Interim $(31 \mathrm{~km}$ vs. $79 \mathrm{~km})$, it is still coarse enough that a distributed model would not have changed the results dramatically in this regard. The two hydrological models selected to evaluate the performance of the various climate datasets, GR4J and HMETS, are flexible and adaptable and have been shown to perform well in a wide range of climates and hydrological regimes (Arsenault al., 2015, 2018; Martel et al., 2017; Valery et al., 2014; Perrin et al., 2003). It was decided to perform the study using two hydrological models in order to assess the impacts of the climate data selection on the overall uncertainty of the hydrological modelling simulations.

\subsubsection{The GR4J hydrological model}

The GR4J hydrological model (Perrin et al., 2003) is a lumped and conceptual model that is based on a cascadingreservoir production and routing scheme. Water is routed from these reservoirs to the outlet in parameterized unit hydrographs. While the original GR4J model includes four calibration parameters, the version used in this study had six calibration parameters in order to include a snow-accounting and snowmelt routine, namely CEMANEIGE (Valéry et al., 2014). This GR4J-CEMANEIGE (GR4JCN) combination has shown excellent results in studies across the globe (Huet, 2015; Raimonet et al., 2017, 2018; Youssef et al., 2018; Riboust et al., 2019; Wang et al., 2019), including in Canada and the United States. It requires daily precipitation, temperature and potential evapotranspiration (PET) as inputs. The PET was computed using the Oudin formulation (2005) as it was shown to be simple yet efficient when used in GR4JCN. Furthermore, the choice of PET is more sensitive than in other simple hydrological models because GR4J does not scale the input PET to adjust its overall mass balance. In- stead, a parameter is included that allows exchanges between underground reservoirs of neighbouring catchments.

\subsubsection{The HMETS hydrological model}

The HMETS hydrological model (Martel et al., 2017) is more complex than GR4JCN, and as such has more calibration parameters (21). While it is similar conceptually to GR4JCN, it has four reservoirs instead of two (surface runoff, hypodermic flow from the vadose zone reservoir, delayed runoff from infiltration and groundwater flow from the phreatic zone reservoir), allowing for finer adjustments to the runoff and routing schemes. Its snowmelt module requires 10 of the 21 parameters and was selected specifically to be more robust in Nordic catchments with specific routines for snow accounting, snowmelt, snowpack refreezing, ice formation and soil freezing and thawing. As for PET, it uses the same Oudin formulation as GR4JCN, but HMETS includes a scaling parameter on PET to control mass balance. It has also been used in large-scale hydrological studies and has shown overall good performance and robustness in a myriad of climates and hydrological conditions.

\subsection{Hydrological model calibration}

As will be detailed in the following section, the three precipitation and three temperature datasets were combined in their nine possible arrangements for analysis purposes. It follows that the sheer number of calibrations to be performed ( 3 precipitation datasets $\times 3$ temperature datasets $\times 2$ hydrological models $\times 3138$ catchments) in this study required implementation of automatic model parameter calibration methods. For this study, the CMAES algorithm was implemented because of its flexibility (Hansen, et al., 2003). Indeed, it performs well for small and large parameter spaces such as the 6-parameter and 21-parameter spaces in this study. It was also shown to be robust and is considered to be one of the best auto-calibration algorithms for hydrological modelling (Arsenault et al., 2013).

The hydrological model parameters were calibrated on the entire available record of data for each catchment, foregoing the usual model validation step. This method was chosen for two reasons. First, calibrating on all years ensures that the maximum amount of information from the climate data is present in the parameter set and thus that there is no added uncertainty from choosing calibration and validation years. Second, Arsenault et al. (2018) have shown that the model performance is statistically better when more years are added to the dataset and that validation and calibration skills are not necessarily correlated.

Finally, the calibration objective function was the KlingGupta efficiency (KGE) metric, which is a modified version of the Nash-Sutcliffe efficiency metric that was introduced by Gupta et al. (2009) and Kling et al. (2012). KGE corrects the fact that NSE underestimates variability in the goodness- 
of-fit function. It is defined as a combination of three elements:

$$
\mathrm{KGE}=1-\sqrt{(r-1)^{2}+(\beta-1)^{2}+(\gamma-1)^{2}},
$$

where $r$ is the correlation component represented by Pearson's correlation coefficient, $\beta$ is the bias component represented by the ratio of estimated and observed means, and $\gamma$ is the variability component represented by the ratio of the estimated and observed coefficients of variation.

A perfect fit between observed and simulated flows will return a KGE of 1. Using the mean hydrograph as a predictor returns a KGE of 0 , and a KGE lower than 0 implies that the simulated streamflow is a worse predictor of the observed flows than taking the mean of the observed values. KGE values above 0.6 are generally considered good; however, this is a subjective quantification of the quality of the goodness of fit.

\subsection{Evaluation of the ERA5, ERA-I and observed datasets}

The next steps following the calibration of the hydrological models on the 3138 catchments were to analyse the raw climate data (precipitation and temperature) at the catchment scale. This analysis was performed by generating the nine possible arrangements of three precipitation and three temperature datasets and comparing their relative differences. Then, after performing the model calibration and hydrological simulation steps, the same type of comparison was performed using the calibration KGE metric as a proxy to the quality of the climate dataset. For example, if a certain combination of precipitation and temperature datasets generates higher KGE calibration scores, it is assumed that the climate data are more likely to be accurate than another dataset that returns lower KGE scores.

The various analyses were conducted on the yearly scale as well as for the winter (December, January and February, or DJF) and summer (June, July and August, or JJA) seasons. The results were then analysed according to their respective catchment locations, climates and sizes in an effort to explain any relationships or differences between the dataset characteristics (i.e. resolution, physics) and their performance (i.e. KGE scores).

\section{Results}

\subsection{Analysis of precipitation and temperature}

The first part of the study was to compare precipitation and temperature values averaged at the catchment scale. Figure 2 shows the mean annual temperatures for the observations and the ERA5 and ERA-Interim reanalysis products for the catchments in this study (top row). It also shows the mean absolute differences between the datasets for the winter (centre row) and summer seasons (bottom row).
The results in Fig. 2 are averaged at the catchment scale in order to preserve the consistency between the climate data and the hydrological modelling results presented further in this paper. It can be seen that the ERA-Interim and ERA5 temperatures are generally similar to the observations, although ERA-Interim displays a warm bias almost everywhere except for the south-eastern United States and a few catchments in Canada, where it has a cold bias.

On the other hand, ERA5 sees a strong reduction in biases compared to those in the ERA-Interim dataset. The western coast of North America clearly still shows some important biases of up to $3{ }^{\circ} \mathrm{C}$ in summer and $-2{ }^{\circ} \mathrm{C}$ in summer, although for most catchments the bias amplitude is smaller. It should be noted that most of the large biases are observed in mountainous areas, where observation networks are generally considered less robust. In the panels representing the differences between ERA5 and ERA-Interim in Fig. 2, it can be seen that the ERA5 product corrects the biases in ERA-Interim; i.e. the areas that were too hot in ERA-Interim are colder in ERA5 and vice versa. The south-eastern USA was particularly problematic for ERA-Interim in the context of hydrological modelling (Essou et al., 2016b), and it will therefore be explored further with ERA5 in the rest of this study.

The precipitation time series from the three datasets in this study were compared in a similar manner to the temperature data, with Fig. 3 showing the mean annual precipitation for the observations and the ERA5 and ERA-Interim reanalysis products for the catchments in this study (top row). Figure 3 also shows the mean absolute differences between the datasets for the winter (centre row) and summer seasons (bottom row).

From Fig. 3, it is clear that there is a good representation of mean seasonal and annual precipitation values across the study domain. For winter, it seems that ERA-Interim and ERA5 are very similar, as the differences between those datasets are small. One exception is the western coast, where a dry bias persists although it has been reduced in ERA5 as compared to ERA-Interim. For the summer period, there is a strong reduction in biases for the eastern half of the United States, where ERA-Interim was problematic. The dry/wet bias pattern of ERA-Interim is strongly reduced in ERA5. However, both reanalysis products are wet in the north, although as will be discussed in Sect. 5.1, this might be related to the quality of the observation datasets in the remote northern catchments.

\subsection{Hydrological model simulations}

The first results obtained in the hydrological modelling portion of this study were the performance of the hydrological models in calibration when driven by the various combinations of precipitation and temperature data. Figure 4 shows the calibration KGE scores for the HMETS (panel a) and GR4JCN (panel b) for the nine combinations of precipitation (three sets) and temperature (three sets). Each boxplot 


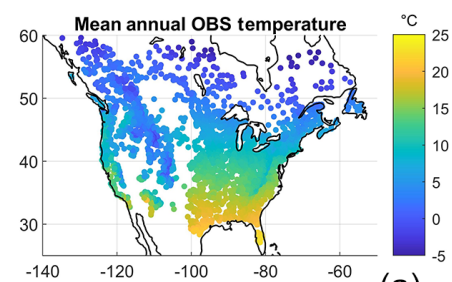

(a)

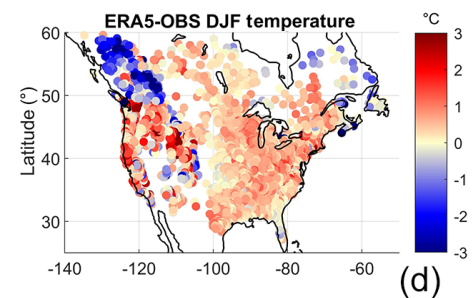

(d)

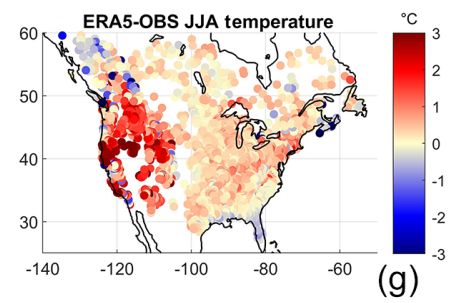

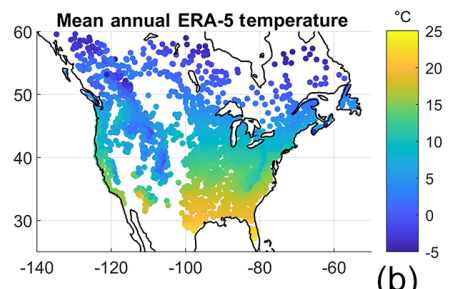

(b)

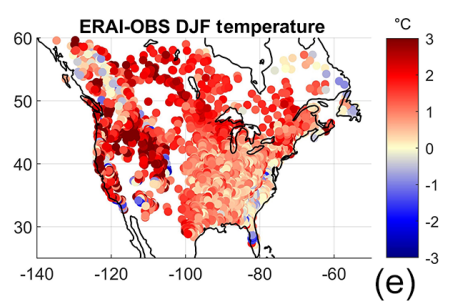

(e)

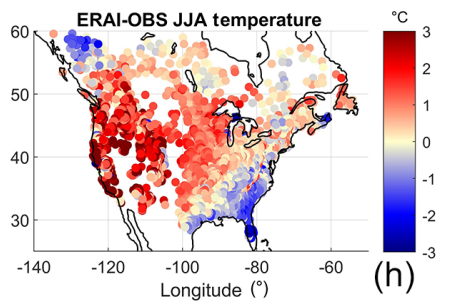

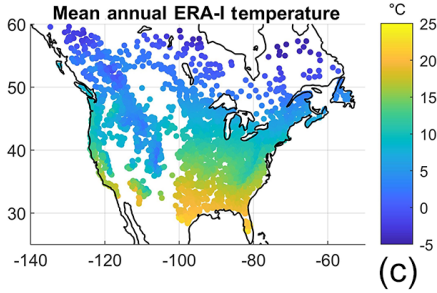

(c)
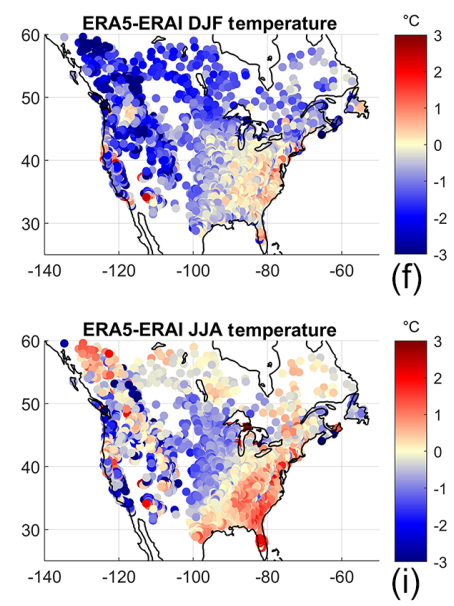

Figure 2. Mean annual temperature for all three datasets $(\mathbf{a}, \mathbf{b}, \mathbf{c})$ and seasonal differences (winter in $\mathbf{d}, \mathbf{e}, \mathbf{f}$, summer in $\mathbf{g}, \mathbf{h}, \mathbf{i})$. All values are in degrees Celsius.

in Fig. 4 contains the KGE scores of all of the catchments in this study.

From Fig. 4, it seems clear that the observations remain the best source of precipitation data for hydrological modelling. It is clear that for hydrological modelling, the ERA5 dataset is a net improvement over the ERA-Interim reanalysis, ranking second after the observations. For the catchments in this study, using ERA5 precipitation allows reduction of the median gap between the older ERA-Interim reanalysis and the observations by approximately $40 \%$. The precipitation data are the main driver behind the differences observed between the datasets, as it can also be seen that the variability linked to the temperature dataset is minimal.

Regarding temperature, ERA5 and the observations provide very similar results, whereas ERA-Interim temperature lags slightly behind. In this sense, the temperature data from ERA5 are marginally more accurate for hydrological modelling at the catchment scale than ERA-Interim and are similar to that of the observed temperature dataset.

From Fig. 4, it is also interesting to note that the hydrological models respond similarly to the various inputs, indicating that the improvements seen with ERA5 are due to the dataset rather than the choice of hydrological model. In general, it can also be seen that HMETS performs better than GR4JCN when using the reanalysis datasets (with a median 0.04 KGE improvement), which is modest but statistically significant using a Kruskal-Wallis non-parametric test.
HMETS and GR4JCN are statistically equivalent in terms of KGE when using the observed meteorological data.

The hydrological modelling KGE metrics were next analysed with respect to the catchment locations, as seen in Figs. 5 and 6. Figure 5 presents absolute values of KGE metrics for all three datasets and both hydrological models. The differences between hydrological models (first vs. second row) are generally small, although the better performance of HMETS is particularly clear over the Rocky Mountains, and especially in the case of both reanalyses. Both hydrological models perform similarly when using observations as inputs compared to reanalysis.

Focusing on the best performing hydrological model results (first row), two major observations can be made. First, hydrological modelling with observations is clearly superior to using both reanalysis datasets for the eastern part of the US, but not so much for the western US and Canada. Second, hydrological modelling performance using ERA5 appears to be consistently superior to ERA-I. To better emphasize these conclusions, Fig. 6 presents differences in KGE metrics between all three datasets. The maps in Fig. 6 are therefore obtained by subtracting the maps from Fig. 5, two at a time. The middle (ERA5) and right (ERA-I) columns present differences in hydrological modelling performance when using reanalyses compared to observations. A blue colour indicates that observations are superior for hydrological modelling, the reverse being true for red colours. This figure provides a clear view of the spatial patterns of hydrological modelling per- 

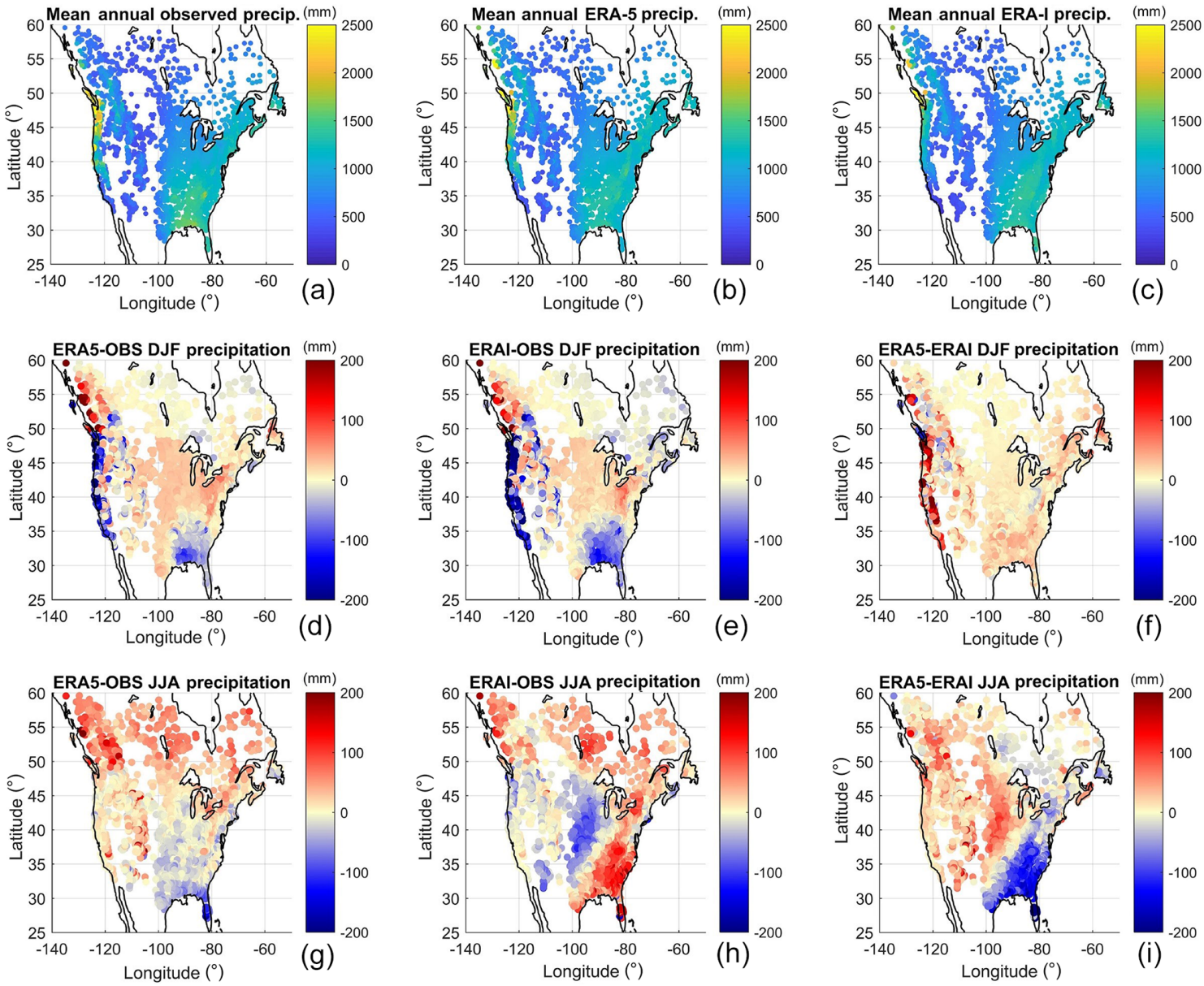

Figure 3. Mean annual precipitation for all three datasets $(\mathbf{a}, \mathbf{b}, \mathbf{c})$ and seasonal differences (winter in $\mathbf{d}, \mathbf{e}, \mathbf{f}$, summer in $\mathbf{g}, \mathbf{h}$, i). All values are in $\mathrm{mm} \mathrm{yr}^{-1}$.
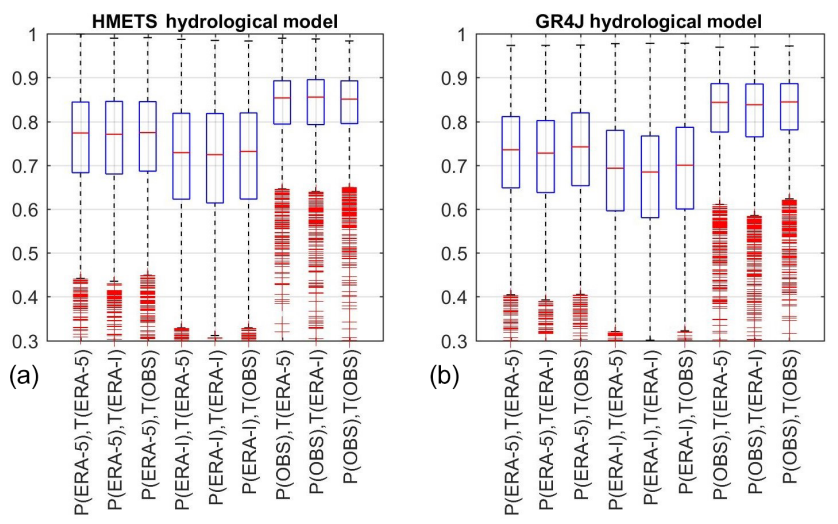

Figure 4. Distribution of calibration KGE scores for all watersheds as a function of meteorological inputs for HMETS (a) and GR4JCN (b).

formance. Observations are clearly superior to reanalyses for the eastern half of the US. This corresponds to the zone with relatively large summer precipitation biases presented earlier in Fig. 3. Outside of this zone, both reanalyses perform similarly to observations, and especially so for ERA5. The lefthand side of Fig. 6 testifies to the uniform and significant improvement in hydrological modelling performance when using ERA5 compared to its predecessor ERA-I.

To gain a better understanding of the reasons behind these observations, hydrological modelling performance was analysed by looking at watershed size (Fig. 7), elevation (Fig. 8) and climate zone (Figs. 9 and 10). In those three cases, the results are only shown for the HMETS hydrological model, since the results for GR4J are similar, albeit with a small degradation in modelling performance, as shown in the preceding figures.

Since all three gridded datasets have different spatial resolutions, Fig. 7 looks at modelling performance for watersheds grouped under four different size classes. The patterns are consistent across all four size classes and similar to those of Fig. 4, with observations being best for all classes, followed by ERA5 and then ERA-I. However, it can be seen that hydrological modelling performance gets progressively better for larger watersheds for all three datasets. This is par- 

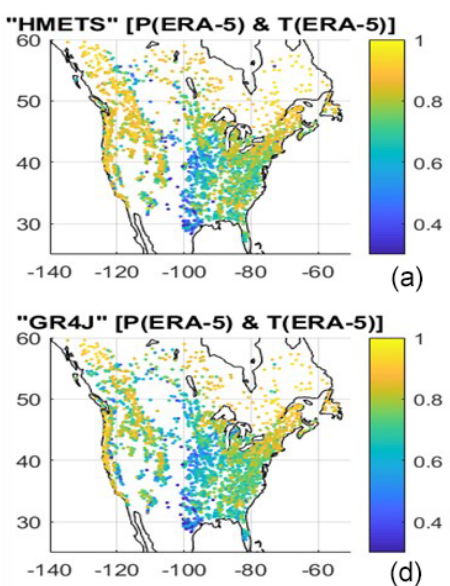

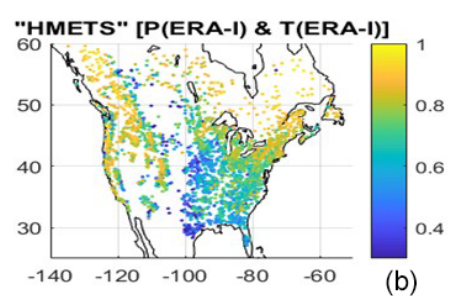

(b)

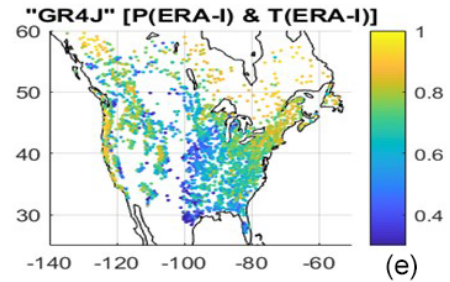

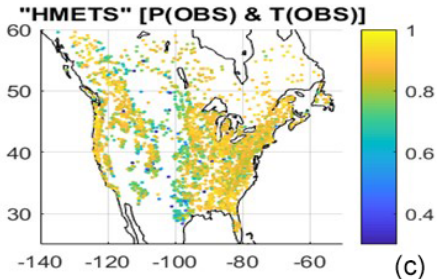

(c)

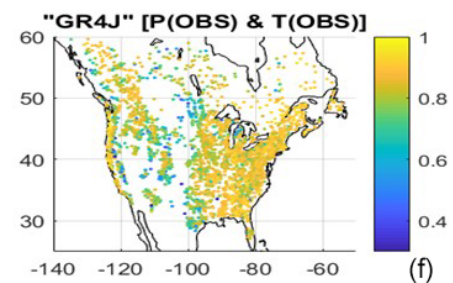

Figure 5. Spatial distribution of Kling-Gupta efficiency metrics for all 3138 watersheds for the HMETS model (a, b, c) and GR4J model (d, e, f), and for ERA5 (a, d), ERA-I (b, e) and observations $(\mathbf{c}, \mathbf{f})$.
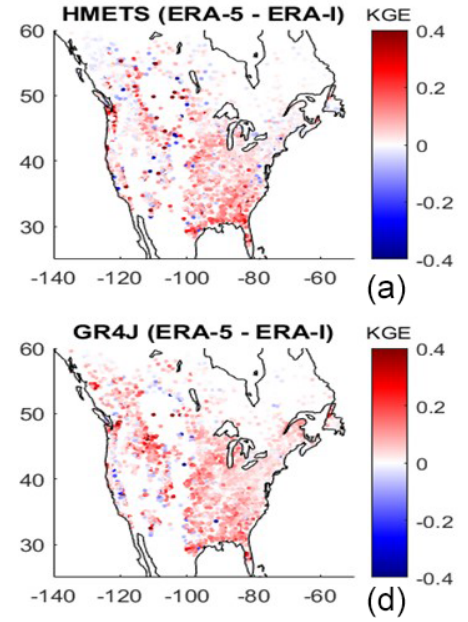
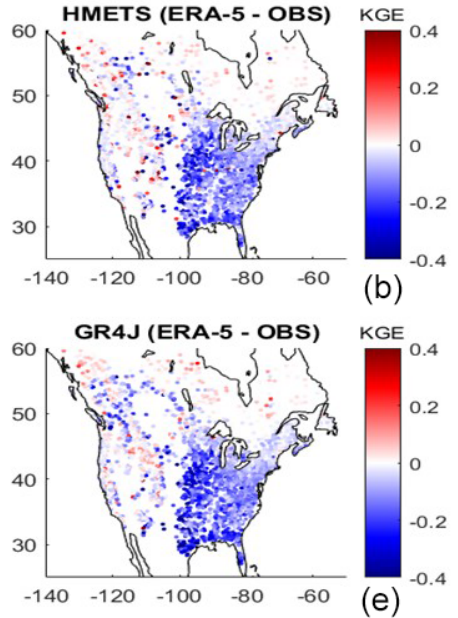

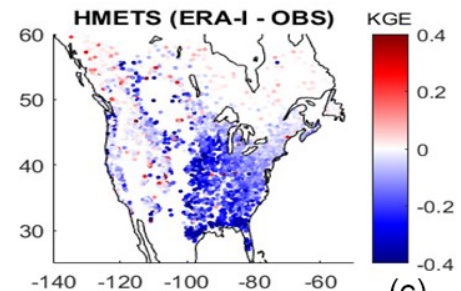

(C)

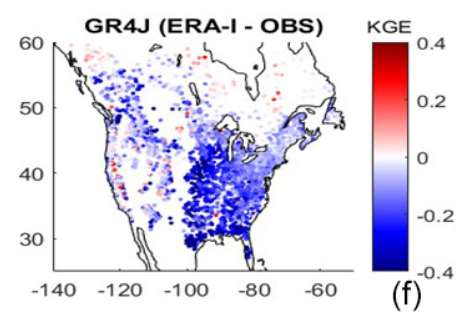

Figure 6. Spatial distribution of the difference of Kling-Gupta efficiency metrics between the three datasets for all 3138 watersheds, for the HMETS model (a, b, c) and GR4J model (d, e, f).

ticularly clear for both reanalyses. While observations perform better at all scales, the gap with reanalysis gets smaller as catchment size increases. The interquartile range (defined by the solid rectangle of the boxplot) is roughly constant for observations, but consistently decreases for both reanalyses. Therefore, a larger proportion of smaller-size watersheds is challenging for hydrological modelling than for larger-size watersheds. Differences between ERA5 and ERA-I stay constant across all size classes.

Figure 8 presents the same data but as a function of watershed elevation, separated once again into four classes. Mean watershed elevation is mapped in Fig. 1. Figure 8 shows a strong dependence of hydrological modelling results on watershed elevation. Observations clearly perform better for the low-elevation $(<500 \mathrm{~m})$ watersheds, but differences rapidly shrink, with ERA5 actually performing as strongly and even better than observations for the last two elevation classes. It is relevant to stress that over $60 \%$ of all watersheds are included in the first elevation class and that most of the eastern US watersheds are within the first two elevation classes. Results from Fig. 7 could therefore be influenced by watershed location in addition to elevation. It is also clear that ERA-Interim temperature gets progressively less competitive as the elevation rises, being significantly less efficient than ERA5 and the observations in the high-elevation groups.

The data were finally analysed by climate zone groupings. Figure 9 presents North America's climate classes from the Köppen-Geiger classification (Peel et al., 2007). It can be seen that North America displays four of the five main climate zones, with the exception of the equatorial climate. In total, 13 classes were kept for this analysis. Figure 10 presents hydrological modelling results for each of those 13 zones. 

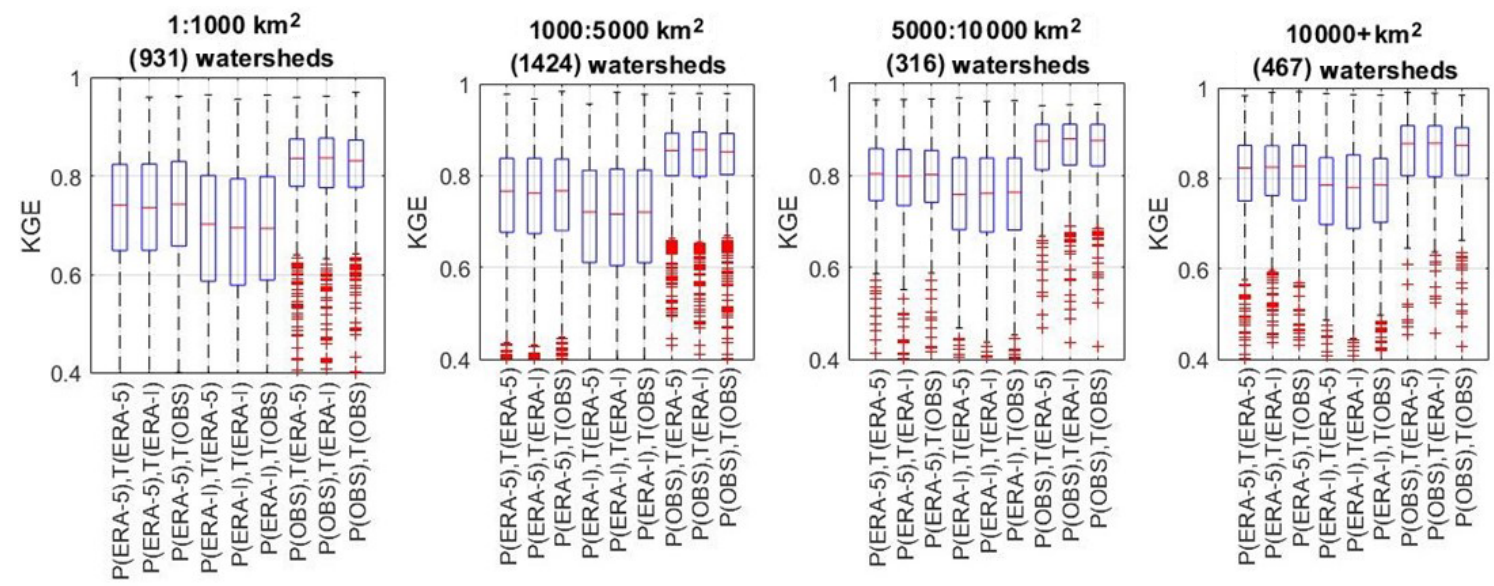

Figure 7. Distribution of the Kling-Gupta efficiency metrics for various watershed surface areas, for hydrological model HMETS.
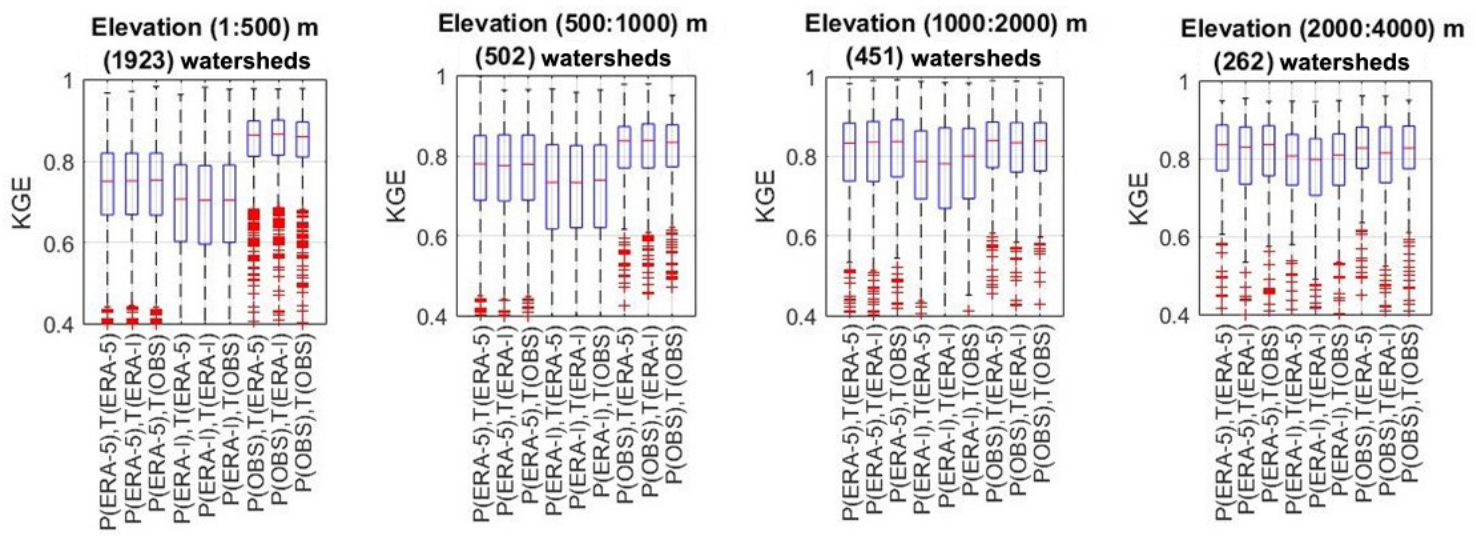

Figure 8. Distribution of the Kling-Gupta efficiency metrics for various elevation bands, for hydrological model HMETS.

Results indicate that dataset performance and relative performance strongly depend on the climate zone. This is not surprising since performance was already shown to display spatial patterns. From Figs. 9 and 10, it is apparent that the ERA5 dataset is systematically better than ERA-Interim for all climate zones and that the observations are clearly superior to ERA5 for the Cfa and Dfa climate zones. Elsewhere, the differences are less pronounced. The Cfa and Dfa climate zones are the two main climate zones in the eastern US, which were shown to be problematic for the reanalysis datasets. Furthermore, ERA5 fares better than the observations in the northern parts of Canada and in the mountainous regions with climate zones Dfc and BSh, respectively. This observation will be discussed further, in Sect. 5.2. Figure 11 summarizes these results with the use of the Kruskal-Wallis statistical significance test to determine the best dataset for each climate zone. The Kruskal-Wallis hypothesis test is a non-parametric test to evaluate whether two samples originate from the same distribution. In Fig. 11, the green, yellow and red colours, respectively, indicate the best, second best and worst datasets for each climate zone. If two datasets share a colour for the same climate zone, the distribution of KGE values is considered to not be statistically different. Results indicate that there are no differences in hydrological modelling performance between ERA5 and observations over 9 of the 13 climate zones. For the other four regions (all in the eastern United States - Bsk, Cfa, Dfa, Dfb), using observations will result in a statistically significantly better hydrological modelling performance. ERA-I is the worst performing dataset over eight climate zones. In the remaining five zones, Bsh (3), Csa (53), Dsc (33), EF (3) and ET (15), all three datasets perform identically from a statistical viewpoint. These zones share in common the fewest watersheds and the most extreme climates (arid and polar).

In order to better explore the differences related to the watershed locations and properties, three catchments of different hydrological regimes were analysed in depth. Figure 12 presents the hydrological modelling KGE difference for HMETS between ERA5 and the observation dataset (first column) along with the mean monthly precipitation (second column), mean monthly temperature (third column) and mean annual hydrograph (fourth column). Results are pre- 


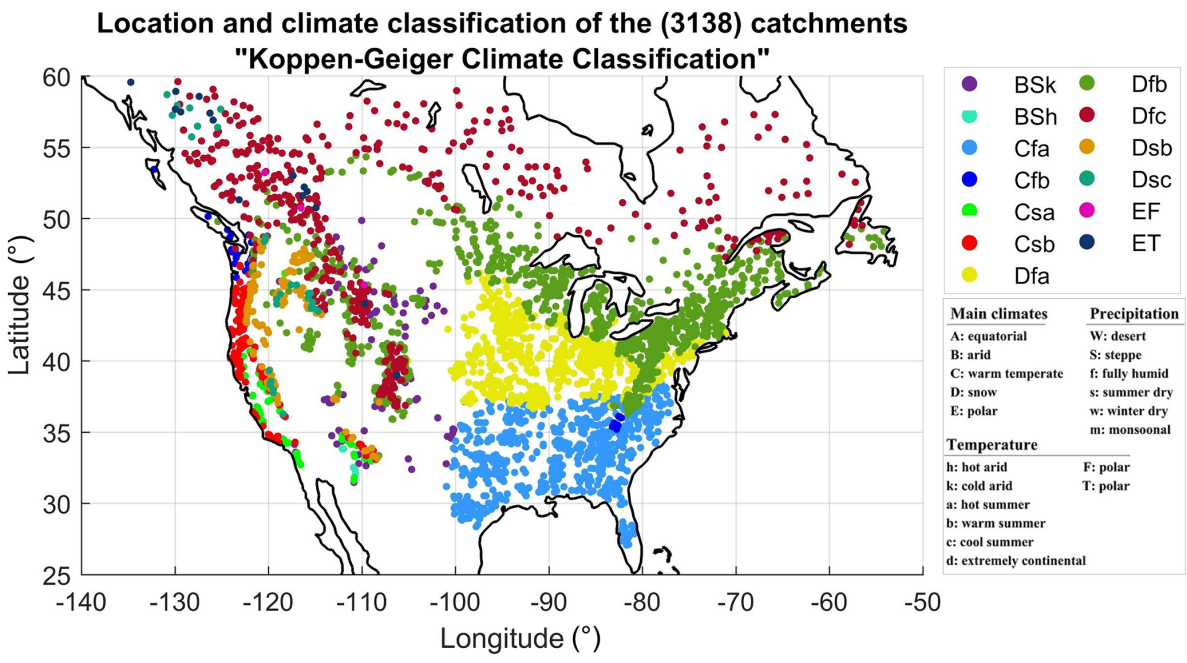

Figure 9. Köppen-Geiger climate classification of the North American watersheds presented in this study.
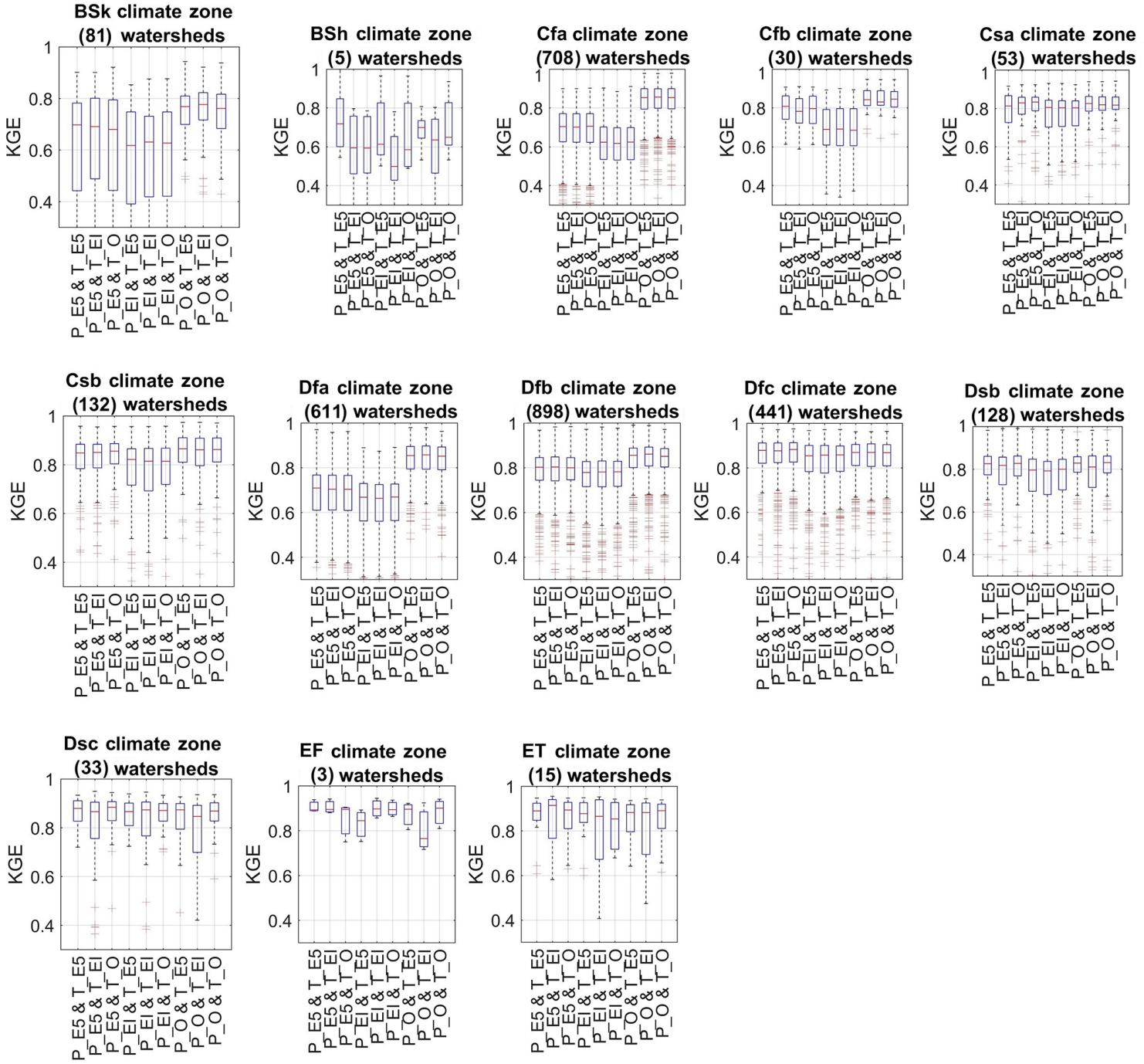

Figure 10. Distribution of the Kling-Gupta efficiency metrics for the 13 climate zones of Fig. 9, for hydrological model HMETS. 


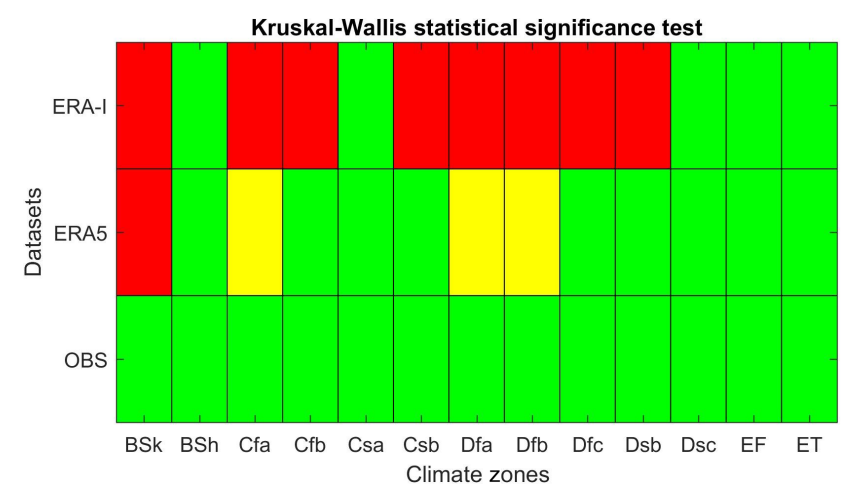

Figure 11. Results of the Kruskal-Wallis statistical significance test to determine the best dataset for hydrological modelling as observed through the KGE metric, for each climate zone. The green, yellow and red colours, respectively, indicate the best, second best and worst datasets for each climate zone.

sented for the Ouiska Chitto Creek near Oberlin, Louisiana, USA (first row), the Grande Rivière à la Baleine in Quebec, Canada (centre row) and the Cosumnes River at Michigan Bar, California, USA (bottom row). Table 1 shows summarized statistics for the three catchments.

The first row in Fig. 12 presents a catchment in the south-eastern United States, which is a region in which the reanalysis-driven hydrological models are unable to perform as well as the observation-driven models. ERA-Interim has a clear precipitation seasonality problem, being too dry except for the summer months, where there is a large overestimation of precipitation compared to the observations. This seasonality problem is mostly solved by ERA5, but a dry bias persists all year, as shown in Fig. 3. The temperatures between the three datasets are practically identical, which means that evapotranspiration should be relatively constant between the products. The lack of precipitation should therefore become apparent in the simulated hydrograph; however, the streamflow is higher for ERA5 than for the observations, when the opposite would normally be expected. It is important to note that the hydrological model can adapt its mass balance by adjusting the potential evapotranspiration scaling, which it has clearly done in this case. The difference in hydrological modelling then comes from the temporal distribution of precipitation, and it can be seen that the ERA5 winter precipitations are relatively lower in winter than for the rest of the year. The PET scaling therefore attempts to reduce evaporation for the entire year, but does not compensate enough to account for this difference in winter. Indeed, it can be seen that the observed hydrograph is underestimated by ERA5 and ERAInterim for that period in the south-eastern United States.

The second catchment is located in northern Quebec, Canada, and as such is in a remote and sparsely gauged region. In this case, it can be seen that the ERA5-driven KGE metric is superior to that obtained using the observations. One key difference between the reanalysis and ob- served datasets is the precipitation, where ERA5 and ERAInterim both show more precipitation than the observations. Again, the temperatures are practically identical, meaning that the potential evapotranspirations, although weak in that region, are very similar. The mean annual hydrograph is also very similar between ERA-Interim and the observations, but it can be seen that the ERA5 model overestimates streamflow in winter while matching the snowmelt peak flows more closely than the other datasets. The difference in KGE in this case comes from a better matching of peak flows, which counts more heavily towards the KGE than the low flows.

The third catchment, located in the west, is characterized by large precipitation systems in autumn and winter, with a months long dry spell in summer. ERA5 mostly corrected ERA-Interim's strong underestimation of precipitation for that catchment, as is the case for most western coast catchments as seen in Fig. 3. ERA5 temperatures are slightly cooler and are more in line with the observations. In terms of hydrological modelling, ERA-Interim underestimates the average streamflows year-round, while ERA5 slightly overestimates them in winter. As seen in Table 1, the ERA5 dataset managed to improve the KGE from 0.83 (ERA-Interim) to 0.87 , as compared to the reference of 0.90 obtained with the observed data. The improvements in precipitation in ERA5 for this region thus seem to translate to improved hydrological modelling compared to using ERA-Interim, which confirms the findings of Fig. 6 .

\section{Discussion}

This study aims to evaluate the ERA5 reanalysis product as a potential reference dataset for hydrological modelling. The ERA5 reanalysis was compared to the ERA-Interim and observation datasets when used in two hydrological models covering 3138 catchments in North America. This section aims to analyse and explain the results obtained in light of the literature and properties of the ERA5 reanalysis. First, differences in climate and hydrological data will be investigated, followed by an analysis based on climate classifications and catchment size. Finally, limitations of the study and recommendations for future work will be provided.

\subsection{Differences in temperature and precipitation between the ERA5, ERA-I and observation datasets}

In this study, the observations are taken as the reference dataset and ERA5 is compared to both the observations and ERA-Interim. This allows validation of both the improvement in ERA5 with respect to ERA-Interim as well as evaluation of the possibility of using ERA5 reanalysis data as inputs to hydrological models to overcome potential deficiencies of observation networks, related to either quality and/or availability. 
Table 1. Summary of physical and hydrological modelling statistics for the three catchments presented in Fig. 11.

\begin{tabular}{lrrrrrrr}
\hline & & & & & \multicolumn{2}{c}{ KGE in calibration } \\
\cline { 4 - 7 } Catchment & $\begin{array}{r}\text { Outlet latitude } \\
\text { (dec. deg.) }\end{array}$ & $\begin{array}{r}\text { Outlet longitude } \\
\text { (dec. deg.) }\end{array}$ & $\begin{array}{r}\text { Outlet } \\
\text { elevation (m) }\end{array}$ & $\begin{array}{r}\text { Catchment } \\
\left.\text { area (km }{ }^{2}\right)\end{array}$ & $\begin{array}{r}\text { ERA5 } \\
\text { dataset }\end{array}$ & $\begin{array}{r}\text { ERA-I } \\
\text { dataset }\end{array}$ & $\begin{array}{r}\text { OBS } \\
\text { dataset }\end{array}$ \\
\hline Ouiska Chitto (south-eastern USA) & 30.93 & -92.98 & 53 & 1320 & 0.65 & 0.49 & 0.87 \\
Grande Baleine (northern Canada) & 55.08 & -73.10 & 389 & 36300 & 0.94 & 0.94 & 0.92 \\
Cosumnes River (western USA) & 38.60 & -120.68 & 696 & 1388 & 0.87 & 0.83 & 0.90 \\
\hline
\end{tabular}
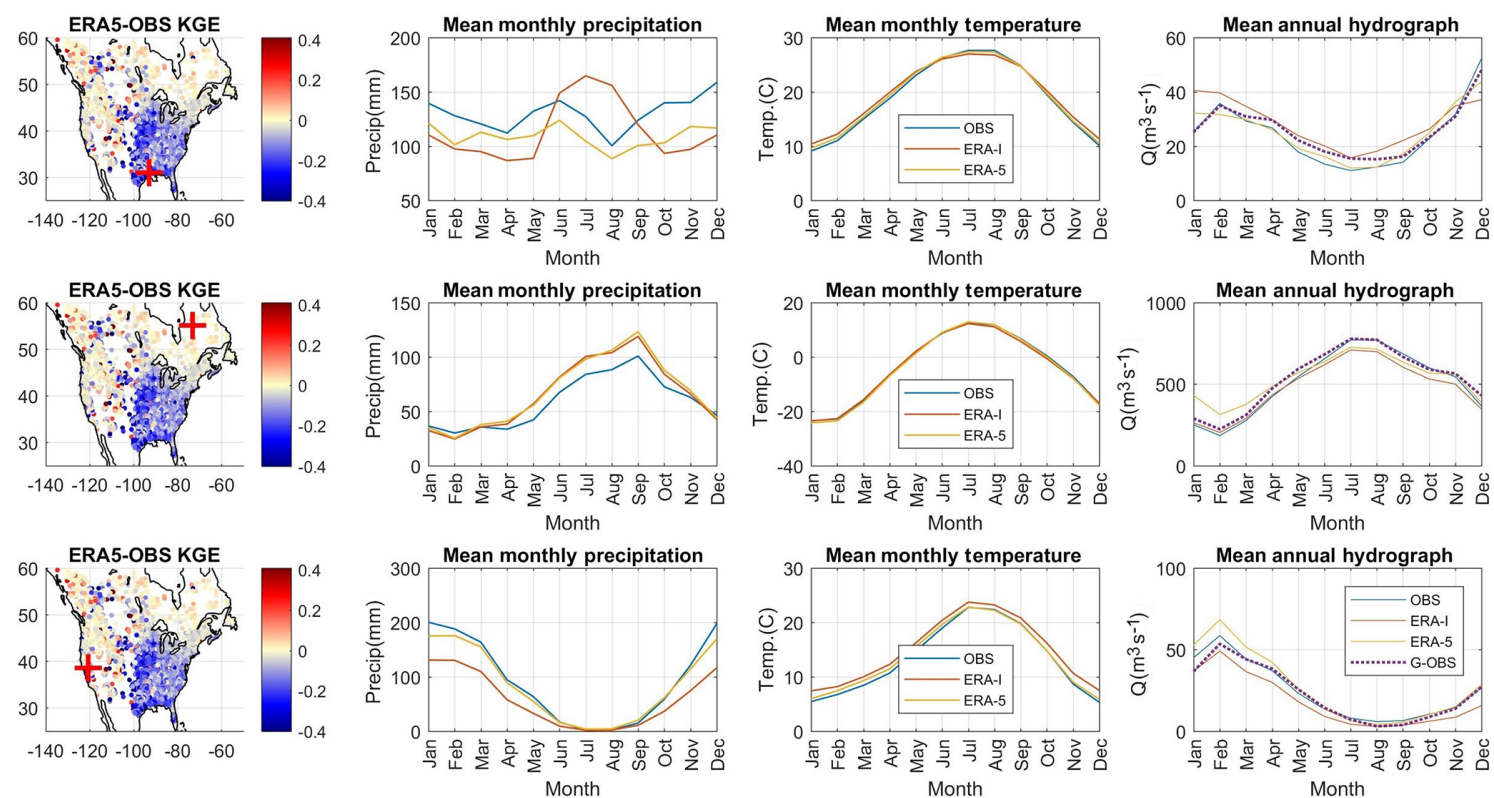

Figure 12. Difference in hydrological modelling performance, mean monthly precipitation and temperature and mean annual hydrograph using ERA-I and ERA5 observations (OBS) and streamflow observations (G-OBS) on three dissimilar catchments: Ouiska Chitto Creek (top row), Grande Rivière à la Baleine (centre row) and Cosumnes River (bottom row).

The evaluation of ERA5 temperature and precipitation variables compared to ERA-Interim and the observation datasets showed that ERA5 systematically reduced biases present in ERA-Interim for the temperature variables, whereas precipitation was generally also less biased, although to a lesser degree. There are remaining precipitation biases on the western coast of North America with ERA5, but from Fig. 2 it can bee seen that the scale of these biases is dependent on the season. In the south-eastern United States, ERA5 largely corrects biases that were present in the ERAInterim dataset and led to relatively poor hydrological modelling in a few studies (e.g. Essou et al., 2016b). As for temperature, Fig. 2 shows that summer temperatures in ERA5 are mostly too high for the catchments west of the Rocky Mountains but are improved over the ERA-Interim data. There is also an interesting pattern of biases between the eastern and western coasts (Figs. 2 and 3), which could be partly explained by some processes not being accounted for in ERA5, notably the high-amplitude ridge trough wave patterns which have seen a recent increase allowing severe weather in both the east and west simultaneously (Singh et al., 2016; Raymond et al., 2017), although ERA5 did improve the representation of many processes since ERA-I (Hoffmann et al., 2019).

It is important to note that these perceived biases suppose that the observation data are perfect. In reality, at the catchment scale, one would expect that the observations would be far from perfect and contain errors due to location representativeness, precipitation undercatch, and missing data due to station malfunction or instrument replacement, for example. However, the observation data are the best estimates available, which makes them the de facto reference dataset. This means that although Figs. 2 and 3 show ERA5 and ERA-Interim as containing some important biases on western North America, it is possible that these biases are caused by biases in the station data relative to the catchment size. The reanalysis products also have the advantage of being driven by spatialized sources such as satellites, which can help in estimating precipitation and temperature data in 
regions where the weather station network is deficient or sparse.

\subsection{Differences in hydrological simulations using ERA5, ERA-I and observation data as inputs to hydrological models}

One way to evaluate the quality of the observation and reanalysis data is to use hydrological models as integrators to compare simulated and observed streamflow, which can act as an independent validation variable. In an attempt to independently assess precipitation and temperature data for each dataset, all possible combinations of precipitation and temperature were fed to two hydrological models, which were then calibrated for each combination. This was to remove any bias caused by parameter sets calibrated on one single dataset, which would obviously be favoured in the resulting analysis. As was the case for the climatological variables, the observed streamflows act as the reference hydrometric data and are considered unbiased. Of course, in reality streamflow gauges contain various sources of errors (Di Baldassarre and Montanari, 2009), but for this study they are the best available estimates. This hypothesis could have a small effect on the conclusions of this study. For example, if a certain combination of precipitation and temperature datasets generates higher KGE calibration scores, it is assumed that the climate data are more likely to be correct than another dataset that returns lower KGE scores. This could be incorrect in some instances where the error actually comes from the streamflow data; however, on average over the 3138 catchments this effect should not influence the results.

The results in Fig. 4 showed that the hydrological models driven with the observed precipitation generally provide the most representative simulated hydrographs, with KGE values exceeding those of the ERA5-precipitation-driven hydrological models by 0.1 on average, which is a significant difference. ERA5 precipitation is also shown to be clearly better than ERA-Interim precipitation on average for the catchments in this study. Another interesting aspect is that in Fig. 4, replacing observed temperatures with ERA5 temperatures marginally improves the hydrological modelling skill. While not a significant difference, this attests to the quality of the ERA5 temperatures in general for hydrological modelling. Therefore, the differences observed in the hydrological modelling performance are almost entirely due to the precipitation data quality. The rest of this study will thus focus on the precipitation and hydrological modelling and forego further analysis of temperature data.

Also of note is that in general, ERA5-driven hydrological simulations are less skillful than those driven by observations. However, there are some catchments - mostly in the mountainous regions of the western United States and in northern Canada - where use of ERA5 leads to improved hydrological simulations. This is probably due to the difficulty in installing weather stations and obtaining representative ob-
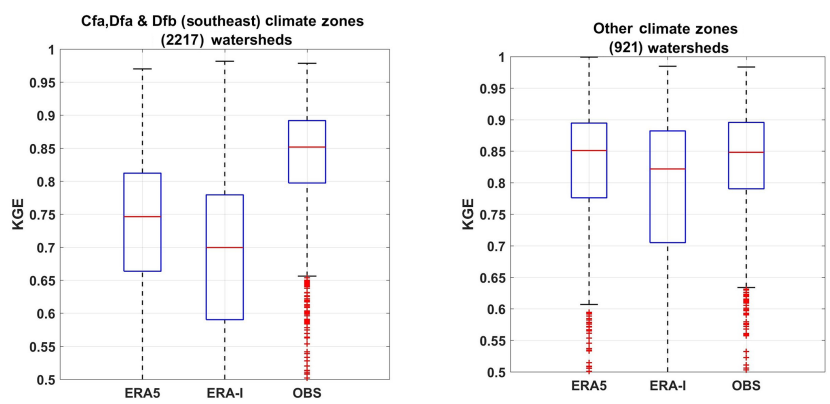

Figure 13. Distribution of the Kling-Gupta efficiency metrics for the 3 north-eastern US climate zones (Cfa, Dfa, Dfb) and for all the other 10 climate zones grouped together, for hydrological model HMETS.

servation data in those regions, but it shows that reanalysis data can be used as a replacement for observations for hydrological modelling in these regions, as previously reported by Essou et al., 2016b).

The more detailed spatial (Fig. 6) and climate zone (Figs. 10 and 11) analysis outlined the strong spatial dependence on dataset performance. Observations clearly outperformed ERA5 over the eastern half of the US, where a larger portion of the watersheds used in this study are located. To illustrate this point, Fig. 13 presents modelling performance over the eastern US (grouping climate zones Cfa, Dfa, and $\mathrm{Dfb}$ ) against that of the other 10 climate zones.

Figure 13 paints a much different picture than Fig. 6 since it shows that hydrological modelling with ERA-5 precipitation and temperature is as good as observations everywhere in North America, with the exception of the eastern US. The disproportionate number of watersheds in this region may overemphasize the performance differential between ERA5 and observations as seen in Fig. 6. An interesting fact is that the eastern US is the North American region with by far the highest density of weather stations, as reported by Janis et al. (2002). Theoretically, this could explain why observationbased modelling performs better in this region. However, Fig. 13 shows that observation-based modelling performance is not different in the other regions, whereas reanalysis-based modelling clearly suffers over the eastern US. This was also noted in Essou et al. (2016b). It could mean that reanalyses face a harder challenge in the eastern US, further away from the Pacific Ocean control on atmospheric circulation. A large proportion of summer and autumn precipitation in these zones comes from convective storms. Eastern Canadian watersheds are well modelled using reanalyses, but the hydrological behaviour of most of those watersheds is dominated by the spring flood, which is largely controlled by temperature, which is very well reproduced by both reanalyses.

Alternatively, this could also mean that eastern US watersheds are in fact more difficult to hydrologically model and that differences are therefore directly linked to network density. Equal performance of ERA5 and observations elsewhere 
would therefore be the result of the improved process representation of ERA5 coupled with some degradation of observations due to the gridded interpolation process between more distant stations. As discussed below, a more precise investigation of modelling performance as a function of station density could shed light on this issue.

\subsection{Differences between the HMETS and GR4J hydrological models}

In this study, two hydrological models were selected to perform the hydrological evaluation of the reanalysis and observation datasets. While both models are conceptually similar, GR4J is simpler than HMETS (two routing processes instead of four, non-scalable PET, much simpler snow model, less than half the number of parameters, etc.). They were shown to perform generally well over all climate zones represented by the catchments used in this study, as can be seen in Fig. 4. Interestingly, both GR4J and HMETS return similar results for any given driving climate dataset. HMETS performs slightly better than GR4J almost everywhere, although that can be attributed to its more flexible model structure and parameterizations that can better adapt to various hydrological conditions.

Since the main objective of this study was to evaluate the ERA5 dataset for hydrological modelling, the interest is not to compare the hydrological model performances, but to compare the ERA5-driven simulations to the others for each model. In both cases, as can be seen in Figs. 4, 6 and 8, ERA5-driven hydrological models clearly outperform the ERA-Interim-driven models, which shows that the precipitation scheme in ERA5 is superior to that in ERA-Interim for hydrological modelling purposes. As stated in Sect. 5.2, temperature seems to play only a minor role in the differences in hydrological modelling.

Furthermore, the observation-driven hydrological models generally perform better than the ERA5-driven models, which confirms that station data should be prioritized when possible. The main caveat to this point is that when the observation station network is of poor quality or too sparse, then ERA5 can be used to fill the voids and get an acceptable hydrological response, as discussed in Sect. 5.2.

\subsection{Analysis of the impacts of catchment size and elevation on the hydrological simulation performance using the ERA-I and ERA5 reanalyses}

One of the major differences between ERA-Interim and ERA5 is the horizontal resolution, improving from 79 to $31 \mathrm{~km}$. This finer resolution should allow for more precise estimations of precipitations and temperatures over smaller catchments that were not adequately represented by ERAInterim. This logic should apply even though the hydrological models are lumped models. Larger catchments could also see some improvements, namely in a better estimation of the terrain elevation, but it is expected that the gain would not be as large as for smaller catchments.

In order to test this hypothesis, the improvements between ERA5 and ERA-Interim in hydrological modelling were sorted according to catchment size, as shown in Fig. 7. It is clear from Fig. 7 that the catchment size is not a good predictor of hydrological simulation improvement. While most catchments see improvements with ERA5 over ERA-Interim, the catchment size does not seem to affect the rate of improvement. This suggests that the improvements do not come from the higher spatial resolution, lending credence to the hypothesis that the enhancements are due to ERA5's improved physics and process representations.

A similar analysis was performed to evaluate the impact of catchment elevation on hydrological modelling skill. It can be seen from Fig. 8 that the elevation plays a significant role in the hydrological model's ability to estimate streamflow. For example, the median and interquartile ranges increase for all datasets as elevation increases. This could be caused by a more rapid hydrological response in higher-elevation and steeper catchments, compared to the slow runoff schemes often found in flat lowlands. The hydrological models being lumped models could contribute to this as large and flat catchments would be more affected by the location of rainfall events compared to steeper ones, especially in the timing of the hydrograph peaks. For the northern catchments, the peaks are caused by snowmelt which is much more uniform than rainfall events, which would minimize this effect.

Another, more probable reason for the reanalysis datasets being stronger in mountainous regions is simply because there are fewer weather stations set up in those areas due to difficulties in accessing and maintaining them. The density of weather stations in the eastern part of the US is typically at least twice as large as for the western part (Janis et al., 2002). In such cases, a reanalysis would provide information that is not conveyed by station data, making it a de facto best estimation of precipitation. In essence, the ERA5 data are not yet as accurate as observations; however, they are able to perform very well in their absence.

Finally, in all the analysed scenarios in this study, ERA5 has always been at least as good as ERA-Interim in terms of hydrological performance. The same is true for the precipitations and temperatures at the catchment scale. From all the results in this study, there does not seem to be any reason or indication that ERA-Interim should continue to be used for hydrological modelling applications, at least in North America. This is not to say that ERA5 is perfect, but it should become the reference for the time being.

\subsection{Limitations}

As is the case with any large-scale comparison studies, some methodological limitations may potentially impact conclusions drawn from the presented results. In terms of hydro- 
logical modelling, this study only uses two lumped conceptual models and one flow criterion (KGE). Both models are lumped, which limits the assessment of the horizontal resolution component of the three datasets. This aspect was however indirectly assessed by looking at the impact of watershed size. Both hydrological models are conceptually similar, but HMETS is more flexible and has more hydrological processes (and parameters). Accordingly, this study was able to look at the impact of parametric space flexibility in dealing with various dataset biases, but not at other issues such as the impact of physically based processes and distributed inputs. A study looking at the latter points would require more complex hydrological models, but at the expense of having to look at far fewer watersheds.

The single streamflow criteria and objective function (KGE), like its Nash-Sutcliffe relative, is weighted towards higher-flow events. Other objective functions would return different results; however, the fact that ERA5 climate data are generally improved in all areas is an indicator that other metrics could potentially see improved results as well, although no test has been performed to that effect in this study. There are several other streamflow criteria which could shed light on differences between datasets, such as extremes. In particular, high-flow extremes have the potential to outline improvements in ERA5 compared to its predecessor ERA-I because of improved resolution and processes. Low flows may also be of interest, although they are typically less well modelled by conceptual hydrological models and are more strongly dependent on temperature, which is very comparable across all three datasets. Finally, there are now several potential other precipitation datasets that could have been included in the comparison (see for example Beck et al., 2017a). However, the goal of this work was a first evaluation of the 1979-2019 ERA5 dataset, because of the potential linked to its spatial and temporal resolutions.

\subsection{Recommendations}

One of the main reasons for the interest in the ERA5 reanalysis resides in its hourly temporal resolution. Therefore, the obvious next step is to investigate sub-daily components, and particularly for precipitation. Sub-daily precipitation is key to investigating the hydrological response of smaller watersheds. However, sub-daily studies raise another set of challenges, notably the absence of a robust baseline hourly meteorological dataset. MSWEP (Beck et al., 2017b) is the best potential candidate at the sub-daily timescale (3-hourly), but the reliability of its sub-daily component is largely unknown. Reliance on hourly weather station data will therefore be required, meaning additional problems, including having to deal with missing data.

The differences noted in the eastern USA raised the question of the potential impact of the density of the station network on the absolute and relative performance of the various datasets. This could be better studied by assigning a net- work density index to each watershed. This could ultimately lead to a better understanding of the role of station density and provide guidance on network improvements or rationalization. It could also be envisioned to extend this work to underdeveloped countries where there is a lower number of observational gauges, where a good quality reanalysis might allow for improved hydrological simulations and better understanding of the regional weather characteristics.

The hydrological performance of ERA5 opens specific avenues of research for streamflow forecasting using ECMWF forecasts. Calibrating hydrological models with ERA5 data could potentially reduce streamflow forecast biases since the reanalysis and forecasts essentially originate from the same model.

\section{Conclusions}

The main objective of this study was to evaluate the ERA5 reanalysis as a potential reference dataset for hydrological modelling over North America, by performing a large-scale hydrological modelling study using ERA5, ERA-Interim and observations as forcing data to two hydrological models. The first assessment showed that ERA5 precipitation and temperature data were greatly improved compared to its predecessor ERA-Interim, although some significant biases remain in the south-eastern United States and North American western coast. These improvements were then shown to translate well to the hydrological modelling results, where both hydrological models showed significant increases in skill with ERA5 as opposed to ERA-Interim. In all cases, ERA5 was consistently better than ERA-Interim for hydrological modelling and as good as observations over most of North America, with the exception of the eastern half of the USA. The lesser performance of reanalyses in this region may reflect some deficiencies in representing precipitation seasonality accurately and may also result from the higher-density network over the eastern USA, thus favouring observations or a combination thereof. We also showed that the catchment size did not impact the hydrological modelling performance; thus, the improvements are not linked to ERA5's model resolution, but to its improved internal physics and assimilation. While some limitations apply to ERA5, it seems that this reanalysis is significantly improved compared to ERA-I and that it should definitely be considered a high-potential dataset for hydrological modelling in regions where observations are lacking either in number or in quality.

Future work should focus on evaluating the sub-daily performance of hydrological modelling with ERA5, testing its quality on other continents, integrating ERA5-based model calibration for hydrological forecasting applications and evaluating its potential for weather network augmentation and rationalization.

Finally, it is important to state that this paper does not advocate the replacement of observed data from weather 
stations by products such as reanalysis, nor should it be interpreted as providing justification to pursue the current trend of decommissioning additional stations. Weather stations will continue to provide the best estimate of surface weather data at the local and regional scales, and there are many fundamental reasons to keep on supporting a strong network of quality weather stations. The results provided in this study for ERA5 show that atmospheric reanalyses have likely reached the point where they can reliably complement observations from weather stations and provide reliable proxies in regions with less dense station networks, at least over North America.

Code and data availability. The gridded observed weather data were downloaded from the Santa Clara repository available here: http://hydro.engr.scu.edu/files/gridded_obs/daily/ncfiles_ 2010 (Maurer et al., 2002).

The Canopex climate and streamflow data can be downloaded from the official data repository available here: http://canopex. etsmtl.net/ (Arsenault et al., 2016).

The USGS streamflow data (USGS, 2019) can be downloaded from the USGS Water Data for the Nation repository available here: https://doi.org/10.5066/F7P55KJN.

ERA-Interim data are available through the ECMWF servers at https://apps.ecmwf.int/datasets/data/interim-full-daily/ (Dee et al., 2011).

ERA5 data are available on the Copernicus Climate Change Service (C3S) Climate Data Store: https://cds.climate.copernicus. eu/cdsapp\#!/dataset/reanalysis-era5-single-levels?tab=form (Hersbach and Dee, 2016).

The HMETS hydrological model is available on the Matlab File Exchange: https://www.mathworks.com/matlabcentral/ fileexchange/48069-hmets-hydrological-model (Martel et al., 2017).

Finally, the GR4J model (Perrin et al., 2003) and CemaNeige snow module (Valéry et al., 2014) are available on the Matlab File Exchange: https://www.mathworks.com/matlabcentral/fileexchange/61720gr4j-rainfall-runoff-model-deterministic-and-stochastic-methodswith-matlab.

Author contributions. MT performed all of the computing work, including ERA5 data download, hydrological modelling and calibration. He performed most of the analysis and wrote the main sections of the paper. FPB contributed to experiment design and data analysis and provided multiple edits to the document. RA, provided expertise on the catchment database and parallel computing. He also participated in the analysis and writing of the document.

Competing interests. The authors declare that they have no conflict of interest.

Financial support. This study has been partly funded by the Egyptian Armed Forces (Ministry of Defense). The Natural Sciences and Engineering Research Council of Canada (NSERC) also partly funded this project through François P. Brissette and Richard Arsenault's respective discovery grants (grant nos. RGPIN-2015-05048 and RGPIN-2018-04872).

Review statement. This paper was edited by Luis Samaniego and reviewed by two anonymous referees.

\section{References}

Albergel, C., Dutra, E., Munier, S., Calvet, J.-C., Munoz-Sabater, J., de Rosnay, P., and Balsamo, G.: ERA-5 and ERA-Interim driven ISBA land surface model simulations: which one performs better?, Hydrol. Earth Syst. Sci., 22, 3515-3532, https://doi.org/10.5194/hess-22-3515-2018, 2018.

Arsenault, R., Poulin, A., Côté, P., and Brissette, F.: Comparison of stochastic optimization algorithms in hydrological model calibration, J. Hydrol. Eng., 19, 1374-1384, 2013.

Arsenault, R., Gatien, P., Renaud, B., Brissette, F., and Martel, J. L.: A comparative analysis of 9 multi-model averaging approaches in hydrological continuous streamflow simulation, J. Hydrol., 529, 754-767, https://doi.org/10.1016/j.jhydrol.2015.09.001, 2015.

Arsenault, R., Bazile, R., Ouellet Dallaire, C., and Brissette, F.: CANOPEX: A Canadian hydrometeorological watershed database, Hydrol. Process., 30, 2734-2736, https://doi.org/10.1002/hyp.10880, 2016 (data available at: http://canopex.etsmtl.net/, last access: December, 2010).

Arsenault, R., Brissette, F., and Martel, J.-L.: The hazards of splitsample validation in hydrological model calibration, J. Hydrol., 566, 346-362, 2018.

Beck, H. E., Vergopolan, N., Pan, M., Levizzani, V., van Dijk, A. I. J. M., Weedon, G. P., Brocca, L., Pappenberger, F., Huffman, G. J., and Wood, E. F.: Global-scale evaluation of 22 precipitation datasets using gauge observations and hydrological modeling, Hydrol. Earth Syst. Sci., 21, 6201-6217, https://doi.org/10.5194/hess-21-6201-2017, 2017a.

Beck, H. E., van Dijk, A. I. J. M., Levizzani, V., Schellekens, J., Miralles, D. G., Martens, B., and de Roo, A.: MSWEP: 3hourly $0.25^{\circ}$ global gridded precipitation (1979-2015) by merging gauge, satellite, and reanalysis data, Hydrol. Earth Syst. Sci., 21, 589-615, https://doi.org/10.5194/hess-21-589-2017, 2017b.

Beck, H. E., Pan, M., Roy, T., Weedon, G. P., Pappenberger, F., van Dijk, A. I. J. M., Huffman, G. J., Adler, R. F., and Wood, E. F.: Daily evaluation of 26 precipitation datasets using Stage-IV gauge-radar data for the CONUS, Hydrol. Earth Syst. Sci., 23, 207-224, https://doi.org/10.5194/hess-23-207-2019, 2019a.

Beck, H. E., Wood, E. F., Pan, M., Fisher, C. K., Miralles, D. G., van Dijk, A. I., McVicar, T. R., and Adler, R. F.: MSWEP V2 global 3-hourly 0.1 precipitation: methodology and quantitative assessment, B. Am. Meteorol. Soc., 100, 473-500, 2019b.

Bengtsson, L., Hagemann, S., and Hodges, K. I.: Can climate trends be calculated from reanalysis data?, J. Geophys. Res.Atmos., 109, D11111, https://doi.org/10.1029/2004JD004536, 2004.

Burn, D. H., Hannaford, J., Hodgkins, G. A., Whitfield, P. H., Thorne, R., and Marsh, T.: Reference hydrologic networks II. 
Using reference hydrologic networks to assess climate-driven changes in streamflow, Hydrol. Sci. J., 57, 1580-1593, 2012.

Chaudhuri, A. H., Ponte, R. M., Forget, G., and Heimbach, P.: A comparison of atmospheric reanalysis surface products over the ocean and implications for uncertainties in air-sea boundary forcing, J. Climate, 26, 153-170, 2013.

Chen, J., Brissette, F. P., and Chen, H.: Using reanalysis-driven regional climate model outputs for hydrology modelling, Hydrol. Process., 32, 3019-3031, 2018.

Citterio, M., van As, D., Ahlstrøm, A. P., Andersen, M. L., Andersen, S. B., Box, J. E., Charalampidis, C., Colgan, W. T., Fausto, R. S., Nielsen, S., and Veicherts, M.: Automatic weather stations for basic and applied glaciological research, Geological Survey of Denmark and Greenland Bulletin, 33, 69-72, 2015.

Dee, D. P., Uppala, S. M., Simmons, A. J., Berrisford, P., Poli, P., Kobayashi, S., Andrae, U., Balmaseda, M. A., Balsamo, G., Bauer, D. P., and Bechtold, P.: The ERA-Interim reanalysis: Configuration and performance of the data assimilation system, Q. J. Roy. Meteorol. Soc., 137, 553-597, https://doi.org/10.1002/qj.828, 2011 (data available at: https:// apps.ecmwf.int/datasets/data/interim-full-daily/, last access: August 2019).

Di Baldassarre, G. and Montanari, A.: Uncertainty in river discharge observations: a quantitative analysis, Hydrol. Earth Syst. Sci., 13, 913-921, https://doi.org/10.5194/hess-13-913-2009, 2009.

Di Giuseppe, F., Pappenberger, F., Wetterhall, F., Krzeminski, B., Camia, A., Libertá, G., and San Miguel, J.: The potential predictability of fire danger provided by numerical weather prediction, J. Appl. Meteorol. Climatol., 55, 2469-2491, 2016.

Emerton, R., Cloke, H. L., Stephens, E. M., Zsoter, E., Woolnough, S. J., and Pappenberger, F.: Complex picture for likelihood of ENSO-driven flood hazard, Nature Commun., 8, 14796, https://doi.org/10.1038/ncomms 14796, 2017.

Essou, G. R., Arsenault, R., and Brissette, F. P.: Comparison of climate datasets for lumped hydrological modeling over the continental United States, J. Hydrol., 537, 334-345, 2016 a.

Essou, G. R., Sabarly, F., Lucas-Picher, P., Brissette, F., and Poulin, A.: Can precipitation and temperature from meteorological reanalyses be used for hydrological modeling?, J. Hydrometeorol., 17, 1929-1950, 2016b.

Essou, G. R., Brissette, F., and Lucas-Picher, P.: The use of reanalyses and gridded observations as weather input data for a hydrological model: Comparison of performances of simulated river flows based on the density of weather stations, J. Hydrometeorol., 18, 497-513, 2017.

Fortin, V., Roy, G., Donaldson, N., and Mahidjiba, A.: Assimilation of radar quantitative precipitation estimations in the Canadian Precipitation Analysis (CaPA), J. Hydrol., 531, 296-307, 2015.

GISS: https://data.giss.nasa.gov/gistemp/stdata/ (last access: June 2019), 2019.

Gupta, H. V., Kling, H., Yilmaz, K. K., and Martinez, G. F.: Decomposition of the mean squared error and NSE performance criteria: Implications for improving hydrological modelling, J. Hydrol., 377, 80-91, 2009.

Hansen, N., Müller, S. D., and Koumoutsakos, P.: Reducing the time complexity of the derandomized evolution strategy with covariance matrix adaptation (CMA-ES), Evolutionary Computation, $11,1-18,2003$.
Hersbach, H. and Dee, D.: ERA5 reanalysis is in production, ECMWF Newsletter 147, ECMWF, Reading, UK, available at: https://www.ecmwf.int/en/newsletter/147/news/ era5-reanalysis-production (last access: May 2020), 2016 (data available at: https://cds.climate.copernicus.eu/cdsapp\#!/dataset/ reanalysis-era5-single-levels?tab=form, last access: May 2020).

Hoffmann, L., Günther, G., Li, D., Stein, O., Wu, X., Griessbach, S., Heng, Y., Konopka, P., Müller, R., Vogel, B., and Wright, J. S.: From ERA-Interim to ERA5: the considerable impact of ECMWF's next-generation reanalysis on Lagrangian transport simulations, Atmos. Chem. Phys., 19, 3097-3124, https://doi.org/10.5194/acp-19-3097-2019, 2019.

Huet, M.: Comparaison de méthodes d'estimation de la recharge des aquifères: exemple de la région Charlevoix-Haute-Côte-Nord (Doctoral dissertation, Université du Québec à Chicoutimi), 2015.

Hutchinson, M. F., McKenney, D. W., Lawrence, K., Pedlar, J. H., Hopkinson, R. F., Milewska, E., and Papadopol, P.: Development and testing of Canada-wide interpolated spatial models of daily minimum-maximum temperature and precipitation for 1961-2003, J. Appl. Meteorol. Climatol., 48, 725-741, 2009.

Janis, M. J., Hubbard, K. G., and Redmond, K. T.: Determining the Optimal Number of Stations for the United States Climate Reference Network, Final Report, Southeast Regional Climate Center Research Paper Series April 2002, 21 pp., 2002.

Kling, H., Fuchs, M., and Paulin, M.: Runoff conditions in the upper Danube basin under an ensemble of climate change scenarios, J. Hydrol., 424, 264-277, 2012.

Lespinas, F., Fortin, V., Roy, G., Rasmussen, P., and Stadnyk, T.: Performance evaluation of the Canadian precipitation analysis (CaPA), J. Hydrometeorol., 16, 2045-2064, 2015.

Lettenmaier, D. P., Alsdorf, D., Dozier, J., Huffman, G. J., Pan, M., and Wood, E. F.: Inroads of remote sensing into hydrologic science during the WRR era, Water Resour. Res., 51, 7309-7342, 2015.

Lindsay, R., Wensnahan, M., Schweiger, A., and Zhang, J.: Evaluation of seven different atmospheric reanalysis products in the Arctic, J. Climate, 27, 2588-2606, 2014.

Lins, H. F.: Challenges to hydrological observations, Bulletin of the World Meterological Organization, v.57(1), 55-58, 2008.

Luo, C., Wang, Z., Sauer, T. J., Helmers, M. J., Horton, R.: Portable canopy chamber measurements of evapotranspiration in corn, soybean, and reconstructed prairie, Agr. Water Manag., 198, 1-9, 2018.

Martel, J. L., Demeester, K., Brissette, F., Poulin, A., and Arsenault, R.: HMETS-A simple and efficient hydrology model for teaching hydrological modelling, flow forecasting and climate change impacts, Int. J. Eng. Educat., 33, 1307-1316, https://dialnet.unirioja.es/servlet/articulo?codigo $=6897050$, 2017 (data available at: https://www.mathworks.com/ matlabcentral/fileexchange/48069-hmets-hydrological-model, last access: October 2016).

Maurer, E. P., Wood, A. W., Adam, J. C., Lettenmaier, D. P., and Nijssen, B.: A long-term hydrologically based dataset of land surface fluxes and states for the conterminous United States, J. Climate, 15, 3237-3251, https://doi.org/10.1175/15200442(2002)015<3237:ALTHBD>2.0.CO;2, 2002 (data available at: http://hydro.engr.scu.edu/files/gridded_obs/daily/ncfiles_ 2010, last access: December 2010). 
McCabe, M. F., Rodell, M., Alsdorf, D. E., Miralles, D. G., Uijlenhoet, R., Wagner, W., Lucieer, A., Houborg, R., Verhoest, N. E. C., Franz, T. E., Shi, J., Gao, H., and Wood, E. F.: The future of Earth observation in hydrology, Hydrol. Earth Syst. Sci., 21, 3879-3914, https://doi.org/10.5194/hess-21-3879-2017, 2017.

Menne, M. J., Williams, C. N., Gleason, B. E., Rennie, J. J., and Lawrimore, J. H.: The Global Historical Climatology Network Monthly Temperature Dataset, Version 4, J. Climate, 31, 98359854, 2018.

Newman, A. J., Clark, M. P., Craig, J., Nijssen, B., Wood, A., Gutmann, E., Mizukami, N., Brekke, L., and Arnold, J. R.: Gridded ensemble precipitation and temperature estimates for the contiguous United States, J. Hydrometeorol., 16, 2481-2500, 2015.

Olauson, J.: ERA5: The new champion of wind power modelling?, Renew. Energ., 126, 322-331, 2018.

Oudin, L., Hervieu, F., Michel, C., Perrin, C., Andréassian, V., Anctil, F., and Loumagne, C.: Which potential evapotranspiration input for a lumped rainfall-runoff model?, Part 2 - Towards a simple and efficient potential evapotranspiration model for rainfallrunoff modelling, J. Hydrol., 303, 290-306, 2005.

Parker, W. S.: Reanalyses and observations: What's the difference?, B. Am. Meteorol. Soc., 97, 1565-1572, 2016.

Peel, M. C., Finlayson, B. L., and McMahon, T. A.: Updated world map of the Köppen-Geiger climate classification, Hydrol. Earth Syst. Sci., 11, 1633-1644, https://doi.org/10.5194/hess-11-16332007, 2007.

Perrin, C., Michel, C., and Andréassian, V.: Improvement of a parsimonious model for streamflow simulation, $\mathrm{J}$. Hydrol., 279, 275-289, https://doi.org/10.1016/S00221694(03)00225-7, 2003 (data available at: https://www.mathworks.com/matlabcentral/fileexchange/61720gr4j-rainfall-runoff-model-deterministic-and-stochasticmethods-with-matlab, last access: June 2018).

Raimonet, M., Oudin, L., Thieu, V., Silvestre, M., Vautard, R., Rabouille, C., and Le Moigne, P.: Evaluation of gridded meteorological datasets for hydrological modelling, J. Hydrometeorol., 18, 3027-3041, 2017.

Raimonet, M., Thieu, V., Silvestre, M., Oudin, L., Rabouille, C., Vautard, R., and Garnier, J.: Landward perspective of coastal eutrophication potential under future climate change: The Seine River case (France), Front. Mar. Sci., 5, 136, https://doi.org/10.3389/fmars.2018.00136, 2018.

Raymond, C., Singh, D., and Horton, R. M.: Spatiotemporal patterns and synoptics of extreme wet bulb temperature in the contiguous United States, J. Geophys. Res.-Atmos., 122, 13-108, 2017.

Riboust, P., Thirel, G., Le Moine, N., and Ribstein, P.: Revisiting a simple degree-day model for integrating satellite data: implementation of SWE-SCA hysteresis, J. Hydrol. Hydromech., 67, 70-81, 2019.

Ruffault, J., Moron, V., Trigo, R. M., and Curt, T.: Daily synoptic conditions associated with large fire occurrence in Mediterranean France: evidence for a wind-driven fire regime, Int. J. Climatol., 37, 524-533, 2017.

Siegert, M. J., Ross, N., and Le Brocq, A. M.: Recent advances in understanding Antarctic subglacial lakes and hydrology. Philosophical Transactions of the Royal Society A: Mathematical, Phys. Eng. Sci., 374, 20140306, https://doi.org/10.1098/rsta.2014.0306, 2016.
Singh, D., Swain, D. L., Mankin, J. S., Horton, D. E., Thomas, L. N., Rajaratnam, B., and Diffenbaugh, N. S.: Recent amplification of the North American winter temperature dipole, J. Geophys. Res.-Atmos., 121, 9911-9928, 2016.

Singh, V. P. and Woolhiser, D. A.: Mathematical modeling of watershed hydrology, J. Hydrol. Eng., 7, 270-292, 2002.

Stearns, C. R. and Wendler, G.: Research results from Antarctic automatic weather stations, Rev. Geophys., 26, 45-61, 1988.

Sun, Q., Miao, C., Duan, Q., Ashouri, H., Sorooshian, S., and Hsu, K. L.: A review of global precipitation data sets: data sources, estimation, and intercomparisons, Rev. Geophys., 56, 79-107, 2018.

Urraca, R., Huld, T., Gracia-Amillo, A., Martinez-de-Pison, F. J., Kaspar, F., and Sanz-Garcia, A.: Evaluation of global horizontal irradiance estimates from ERA5 and COSMO-REA6 reanalyses using ground and satellite-based data, Solar Energy, 164, 339354, 2018.

U.S. Geological Survey: National Water Information System, USGS Water Data for the Nation, https://doi.org/10.5066/F7P55KJN, 2019.

Valéry, A., Andréassian, V., and Perrin, C.: 'As simple as possible but not simpler': What is useful in a temperature-based snow-accounting routine? Part 2 Sensitivity analysis of the Cemaneige snow accounting routine on 380 catchments, J. Hydrol., 517, 1176-1187, https://doi.org/10.1016/j.jhydrol.2014.04.058, $2014 \quad$ (data available at: https://www.mathworks.com/matlabcentral/ fileexchange/61720-gr4j-rainfall-runoff-model-deterministicand-stochastic-methods-with-matlab, last access: February 2020).

Wang, H.-M., Chen, J., Xu, C.-Y., Chen, H., Guo, S., Xie, P., and Li, X.: Does the weighting of climate simulations result in a better quantification of hydrological impacts?, Hydrol. Earth Syst. Sci., 23, 4033-4050, https://doi.org/10.5194/hess-23-4033-2019, 2019.

Whitfield, P. H., Burn, D. H., Hannaford, J., Higgins, H., Hodgkins, G. A., Marsh, T., and Looser, U.: Reference hydrologic networks I, The status and potential future directions of national reference hydrologic networks for detecting trends, Hydrol. Sci. J., 57, 1562-1579, 2012.

Wood, E. F.: Hydrologic measurements and observations: An assessment of needs, in: National Research Council, Hydrologic Sciences: Taking stock and looking ahead, National Academies Press, chap. 3, 67-85, 1998.

Youssef, H., Simon, G., Younes, F., Ghani, C., and Vincent, S.: Rainfall-Runoff modeling in a semi-arid catchment with presence of snow. The Rheraya wadi case study (Marrakech, Morocco), In EGU General Assembly Conference Abstracts, Vol. 20, p. 5214, 2018.

Zhang, Y., Zheng, H., Chiew, F. H., Arancibia, J. P., and Zhou, $\mathrm{X}$.: Evaluating regional and global hydrological models against streamflow and evapotranspiration measurements, J. Hydrometeorol., 17, 995-1010, 2016. 